\title{
Understanding active school travel through the Behavioural Ecological Model
}

Ginja, S., Arnott, B., Namdeo, A., \& McColl, E. (2017). Understanding active school travel through the Behavioural Ecological Model. Health Psychology Review, 12(1), 58-74.

https://doi.org/10.1080/17437199.2017.1400394

Link to publication record in Ulster University Research Portal

\section{Published in:}

Health Psychology Review

Publication Status:

Published (in print/issue): 23/11/2017

DOI:

10.1080/17437199.2017.1400394

\section{Document Version}

Publisher's PDF, also known as Version of record

\section{General rights}

Copyright for the publications made accessible via Ulster University's Research Portal is retained by the author(s) and / or other copyright owners and it is a condition of accessing these publications that users recognise and abide by the legal requirements associated with these rights.

\section{Take down policy}

The Research Portal is Ulster University's institutional repository that provides access to Ulster's research outputs. Every effort has been made to ensure that content in the Research Portal does not infringe any person's rights, or applicable UK laws. If you discover content in the Research Portal that you believe breaches copyright or violates any law, please contact pure-support@ulster.ac.uk. 


\section{Understanding active school travel through the Behavioural Ecological Model}

\section{Samuel Ginja, Bronia Arnott, Anil Namdeo \& Elaine McColl}

To cite this article: Samuel Ginja, Bronia Arnott, Anil Namdeo \& Elaine McColl (2018)

Understanding active school travel through the Behavioural Ecological Model, Health Psychology Review, 12:1, 58-74, DOI: 10.1080/17437199.2017.1400394

To link to this article: https://doi.org/10.1080/17437199.2017.1400394

Accepted author version posted online: 03

Nov 2017.

Published online: 23 Nov 2017.

Submit your article to this journal $\asymp$

Џll Article views: 158

Q View related articles $\circlearrowright$

View Crossmark data $₫$

4 Citing articles: 1 View citing articles 


\title{
Understanding active school travel through the Behavioural Ecological Model
}

\author{
Samuel Ginja ${ }^{\mathrm{a}}$, Bronia Arnott ${ }^{\mathrm{a}}$, Anil Namdeo ${ }^{\mathrm{b}}$ and Elaine McColl ${ }^{\mathrm{a}}$

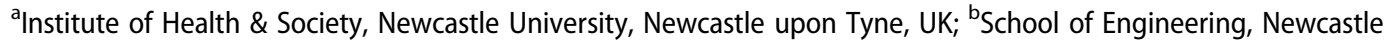 \\ University, Newcastle upon Tyne, UK
}

\begin{abstract}
Active school travel (AST) is an important source of physical activity for children and a conceptual understanding of AST is necessary to inform promotion efforts. The aim of this article is to provide a conceptual analysis of AST. All currently identified AST formulations include intraindividual variables which are often recommended as intervention targets. However, existing literature lacks clarity on precisely how these intra-individual variables might shape specific AST interventions. Moreover, evaluative studies of AST interventions typically fail to specify an underpinning theory or model. To address this limitation, the Behavioural Ecological Model (BEM), not previously addressed in AST, is presented to guide this area of research. Based on specific examples, we draw attention to the role of potential antecedents and potential reinforcers of AST, as well as potential reinforcers of motorised travel. Antecedents and reinforcers may help to explain choices of school travel mode, and to inform and increase intervention options to promote AST. Consistent with the BEM, the provision of more immediate consequences, such as fun and material prizes, is an evidence-based strategy for increasing AST which is likely to be low-cost and easier to deliver than alternative interventions. This approach to the study of AST is expected to contribute to similar analyses in this and other areas of behaviour change research, and to a more useful discussion and treatment of theoretical and conceptual behavioural models.
\end{abstract}

\section{ARTICLE HISTORY}

Received 8 April 2017

Accepted 31 October 2017

\section{KEYWORDS}

Travel behaviour; theory; models; antecedents and reinforcers; contingencies

\section{Background}

Worldwide, most children fail to achieve the recommended $60 \mathrm{~min}$ of moderate-to-vigorous physical activity (MVPA) per day (Hallal et al., 2012). Active school travel (AST) can increase children's MVPA, by as much as 17 min per day in primary school children and 13 min per day in high school students (Martin, Kelly, Boyle, Corlett, \& Reilly, 2016). Yet, in many countries, a decrease in AST over time has been observed (Fyhri, Hjorthol, Mackett, Fotel, \& Kytta, 2011; McDonald, Brown, Marchetti, \& Pedroso, 2011; Van Der Ploeg, Merom, Corpuz, \& Bauman, 2008), although comparisons are often complicated by measurement differences (e.g., 'AST everyday' or 'at least three times a week'). Current data suggest AST levels of $21.4 \%$ in the US (Yang, Ivey, Levy, Royne, \& Klesges, 2016), 43\% in England (DfT, 2016) and 37\% in Australia (Active Healthy Kids Australia, 2015). These figures suggest scope for change in school travel behaviours and the need for effective AST promotion, including the possibility of partway active trips for children living at greater distances from school. A shift to AST also has the potential to contribute to a decrease in pollutants resulting from motorised travel (de Nazelle et al., 2011). 
Developing a behaviour change intervention, such as an intervention to increase AST, often starts with a review of relevant theory (Craig et al., 2013), which can help to specify the occurrence of and motivation for (poor) behaviour and inform its prevention, management or solution (Fleury \& Sidani, 2012). Despite these benefits, most descriptions of AST interventions fail to provide a theoretical rationale (Chillon, Evenson, Vaughn, \& Ward, 2011). The aim of this article is to provide a useful conceptual analysis of AST. Starting with an overview of existing AST formulations, we identify and discuss a key issue: the extent to which previous formulations have informed the development of intervention strategies. We provide an alternative model to conceptualise AST which is expected to result in a clearer pathway to practice.

\section{Current formulations in AST literature}

We will use the word formulation to refer to a theory, model or framework. A scientific theory has been defined as a well-substantiated explanation of some aspect of the natural world, based on a body of facts that have been repeatedly confirmed through observation and experiment (AAAS, 2011). 'Explaining' usually involves identifying a relationship between cause(s) and effect(s), or between independent variable(s) and dependent variable(s) (Keil, 2006). Two terms closely related to theory are 'models' and 'frameworks' and these need to be differentiated from theories. Theories are explanatory principles or statements about a phenomenon, specifying relationships between variables; models tend to have a narrower scope than theories and are usually more descriptive than explanatory; frameworks denote a structure or outline within which phenomena are integrated in various descriptive categories and, as such, do not provide explanations (Nilsen, 2015). However, although different, models and frameworks are often both presented as explanatory which makes the distinction less obvious in practice.

Evaluations of AST interventions have typically been presented without a clear theoretical rationale (Chillon et al., 2011). Yet, there are a considerable number of formulations which have been proposed or developed to account for AST or which have been used in non-experimental AST research. This suggests that much of the theoretical work in AST is not translated into intervention development. For the present review of existing formulations, searches of key relevant terms were performed by a single individual in two main databases. Thirteen formulations were identified, primarily in the context of observational AST research (Table 1).

Current approaches to the study of AST range from a focus on individual variables to environmentally oriented analyses, but all of those identified through our review incorporate, and often emphasise, intra-individual (typically cognitive) variables. In Panter et al.'s framework, for example, youth characteristics and attitudes are hypothesised to influence AST; with youth attitudes proposed to affect perceptions of the environment, and parental characteristics and attitudes proposed to impact on parents' own environmental perceptions and AST decisions (Panter, Jones, \& Van Sluijs, 2008). Another example is the M-CAT, according to which objective elements such as child and family characteristics shape parental and child perceptions of the environment, attitudes and beliefs, and in turn affect AST (Pont, Ziviani, Wadley, \& Abbott, 2011).

Problems with cognitive constructs have been highlighted by many within the behavioural sciences. Three common criticisms include invoking unobservable mental events, treating cognitive processes as causes of behaviour rather than behaviours themselves, and the impossibility of measuring and controlling these variables directly (Chiesa, 1994; Hayes \& Brownstein, 1986). In the anticipation of developing a novel AST intervention, it is on the third criticism that this review will focus: how are intra-individual variables to be targeted or, in other words, how do these variables suggest solutions to promoting AST and inform the production of logic models as part of the development and evaluation of (complex) interventions for enhancing AST?

This problem with cognitive variables is identified in the AST literature by Panter, Jones, van Sluijs, and Griffin (2010): 
Faulkner et al. (2010)

Behavioural Economics

Mendoza et al. (2011)

Social Cognitive Theory, originally by Bandura (1989)

Murtagh et al. (2012)

Theory of Planned Behaviour, combined with a measure of Habit

Strength, originally by Ajzen (2011)

Martin, Moeti, and Pullen-Seufert (2009)

Social Ecological Model, originally by Bronfenbrenner (1979)

Pont et al. (2011)

Model of Children's Active Travel (M-CAT)

Mitra (2013)

Behavioural Model of School Transportation

Hodgson et al. (2012)

Interdisciplinary Model of the Links between Transport and Health in the Context of School Travel

Yang, Schlossberg, Parker, and Johnson (2010)

Conceptual Framework Connecting Preference, Location Choice and Behaviour

Pont, Ziviani, Wadley, Bennett, and Abbott (2009)

ANGELO Framework, originally by Swinburn, Egger, and Raza (1999)
Combines insights from economic thought and behavioural science, particularly principles of operant conditioning such as latency for reward and punishing contingencies. The behaviour studies is typically (but not always) in a market context. Person is seen as a rational agent with a system of preferences, but who also behaves in intuitive and automatic ways.

Personal factors, behavioural patterns and environmental events all operate as interacting determinants influencing one another bidirectionally. Among the personal factors, self-efficacy is considered to be most central.

Intention is the immediate cause of behaviour, resulting from the attitude towards the behaviour, subjective norm and perceived behavioural control, which follow, respectively, from belief's about the behaviour's likely consequences, about normative expectations (or beliefs) of important others, and beliefs about the presence of factors that control behavioural performance.

Insight into automaticity (i.e., habit) can complement the understanding of behaviour provided by a reasoned action approach (i.e., planned behaviour)

Behaviour is the result of multiple levels of influence which interact between themselves, including individual, interpersonal, organisational, community and policy levels.

All levels need to be taken into account to explain behaviour

Objective characteristics of the parent, child and family (e.g., age, gender, income), as well as the objective environment

(physical, political and economic), affect parental and child perceptions of these elements, which in turn affect decisions of school travel mode.

Events during the school trip trigger a feedback loop, as demonstration of the child's skills and abilities, knowledge and experiences are added to previous experiences and modify the objective child, parent and family characteristics. These characteristics, along with any changes in the objective environment, in turn impact parent and child perceptions.

School travel includes escorted vs. independent mobility, and mode choice.

Five domains of causal links between the neighbourhood environment and school travel outcome: external influences, urban environment, household, child and travel. Does not provide an exhaustive description of every variable that might be relevant in any specific dimension.

As children grow, they assume greater control over mobility decisions.

Individual and household factors explain independent (versus escorted) travel.

Transport choices influenced by age, sex and constitutional factors set within a context of individual lifestyle factors; social and community networks; living, working and schooling conditions; and broad socioeconomic, cultural and environmental conditions. However, acknowledges insufficient emphasis on how influences on behaviour occur and on the socioeconomic, cultural, political and environmental conditions.

Incorporates concepts of integral theory and key dimensions of human experience: subjective/interior vs. objective/exterior, and individual vs. collective.

Preference for ATS is formed on the basis of their attitude, affects the decision-making process in their housing-location choice and leads to a residential environment that is more conducive to ATS.

Along with environmental conditions, people's intention to or consideration of using ATS during their residential-location choice impacts on AST.

Analysis Grid for Environments Linked to Obesity (ANGELO) Framework.

Types of environment considered: (1) the physical (man-made physical attributes of the neighbourhood, such as the presence of footpaths, bikeways and controlled crossings, as well as non-man-made factors, such as the weather), (2) the political (power structures, laws, rules and regulations that influence actions), (3) the economic (direct costs associated with activities, as well 


\section{McMillan (2005)}

Conceptual Framework of a Primary-aged Child Travel's Behaviour

Panter et al. (2008)

Conceptual Framework for the Environmental Determinants of Active

Travel in Children

Sirard and Slater (2008)

Ecological and Cognitive Active Commuting Framework

Saiyed and Kennedy (2006)

5 E's Model (unknown original author(s)) as the indirect costs, such as time); and (4) the socio-cultural (community's or society's attitudes, values and beliefs related to health behaviours).

Recognises that, up to a certain age, the final decision about the trip to school is most often made by the parents or carers. Aspects of urban form influence psychosocial factors (perceptions of safety and/or traffic) and/or socioeconomic factors

(household transportation options). These may in turn affect parental decision-making about the child's school travel mode, creating a sequence of causal mediators that intervene between urban form and a child's travel behaviour to school.

Four domains of influence: individual factors (e.g., parental and youth's perceptions and attitudes), those associated with the physical environment (e.g., urban form), external factors outside the most proximal domains of influence (e.g., household income) and main moderators (age, gender and distance to school).

Different levels of the physical environment influence parental and youth perceptions; however, these may be formed from actual attributes, or based on pre-existing views. Travel mode results from both parental and child perceptions.

Different levels of influence: policy, neighbourhood and parent/family.

Socio-demographic factors are presented at the bottom and modify the parent's decision about allowing AST.

Objective assessments of the physical and social environments are assumed to be filtered through parent's perceptions, which are in turn combined with attitudes, beliefs, perceptions of social norms and perceived support with regards to AST.

Preferences and perceptions of the child, other potential sources of information, and resources of the family can further change parental perceptions, although the availability of resources may also act directly on AST.

When the child engages in AST, he/she may alter attitudes and perceptions, theirs and of theirs parents.

Commonly underlying Safe Route to School programmes.

Promotion of active travel needs to combine the $5 \mathrm{E}$ 's: Education (e.g., teaching students and community, providing

information), Encouragement (e.g., getting parents and students excited through special events), Engineering (e.g., improve infrastructure), Enforcement (work with local law enforcement) and Evaluation (monitoring of activities and assessment of intended outcomes). 
Although our findings suggest that changing parental perceptions may be an important intervention strategy, how this could be achieved is currently unknown. The provision of more supportive environments for active commuting might be particularly appropriate as this may itself result in changes in attitudes or perceptions. (Panter et al., 2010, p. 7)

Others have found that parental self-efficacy, i.e., their belief in their child's ability to travel actively to school, was significantly associated with AST (Lu et al., 2015; Mendoza et al., 2010). In one study, the authors concluded that AST interventions should aim to improve this parental psychological construct but gave no indication of how this could be achieved (Mendoza et al., 2010). In another study, both children's and parents' self-efficacy with respect to AST were found to be significantly associated with the occurrence of the behaviour (Lu et al., 2015). Four strategies were recommended to boost child's self-efficacy and therefore AST: community-based interventions to achieve neighbourhood safety, by involving schools, families and communities; increased exposure to supportive role models and positive peer influence; boosting parental self-efficacy (although authors had insufficient data to make specific proposals on this point); and reducing physical and social environmental constraints (Lu et al., 2015). The range of techniques suggested to target self-efficacy is vast and heterogeneous, hindering the delineation of the scope of a 'self-efficacy intervention'. The same argument applies to targeting perceived behavioural control in AST promotion (Murtagh, Rowe, Elliott, McMinn, \& Nelson, 2012). From the current literature, it is unclear what is gained by targeting either self-efficacy with respect to AST or the perceived behavioural control of performing AST, as opposed to targeting the behaviour itself. While our review was not systematic, it is likely that these observations would still hold true had it so been as the formulations found here are comparable to typical behavioural models and theories in terms of the inclusion of intra-individual variables and relations between them.

Another important point to consider when developing the conceptual basis of an intervention is the sustainability of change. In behaviour change literature, a distinction is often made between factors underlying the adoption or initiation of new behaviours and those responsible for their subsequent maintenance (Kwasnicka, Dombrowski, White, \& Sniehotta, 2016). Despite the complexity of some existing AST models, whether individually or environmentally focused, few of them address this issue in an explicit manner. Those which do consider maintenance include the M-CAT which hypothesises that events occurring during the journey to school, whether positive (e.g., socialising with other children, increased fitness) or negative (e.g., road dangers), form the beginning of a feedback loop in which parental and child perceptions are shaped, ultimately impacting on AST (Pont et al., 2011). With a focus on automaticity, Hodgson et al. stress the importance of establishing behavioural habits, or associative responses to environmental cues (e.g., weather), in the maintenance of ATS. They also suggest ways to break bad habits, including strategies such as prompting a review of pros and cons for each travel option, environmental changes, or helping people remember the reasons for their choices (Hodgson, Namdeo, Araujo-Soares, \& Pless-Mulloli, 2012). These approaches suggest the use of cues (verbal or non-verbal) to encourage the initiation of AST, as well as making it a pleasant and rewarding experience, for example, through a positive interaction with other children.

\section{The Behavioural Ecological Model}

One model which tries to avoid the illogical circularity of those discussed above and considers behavioural maintenance is the Behavioural Ecological Model (BEM) (Hovell, Wahlgren, \& Adams, 2009). Deeply rooted in Behaviour Analysis and in the works of B. F. Skinner in particular (Skinner, 1953), this model has been applied to contexts of behaviour change as diverse as stair use (Adams et al., 2006) and school bullying prevention (Dresler-Hawke \& Whitehead, 2009).

Consistent with other AST models, the BEM (Figure 1) considers multiple levels of influence on behaviour, but highlights the interaction between individual and group contingencies (Hovell et al., 2009). The term contingency (or contingency of reinforcement) refers to relationships 


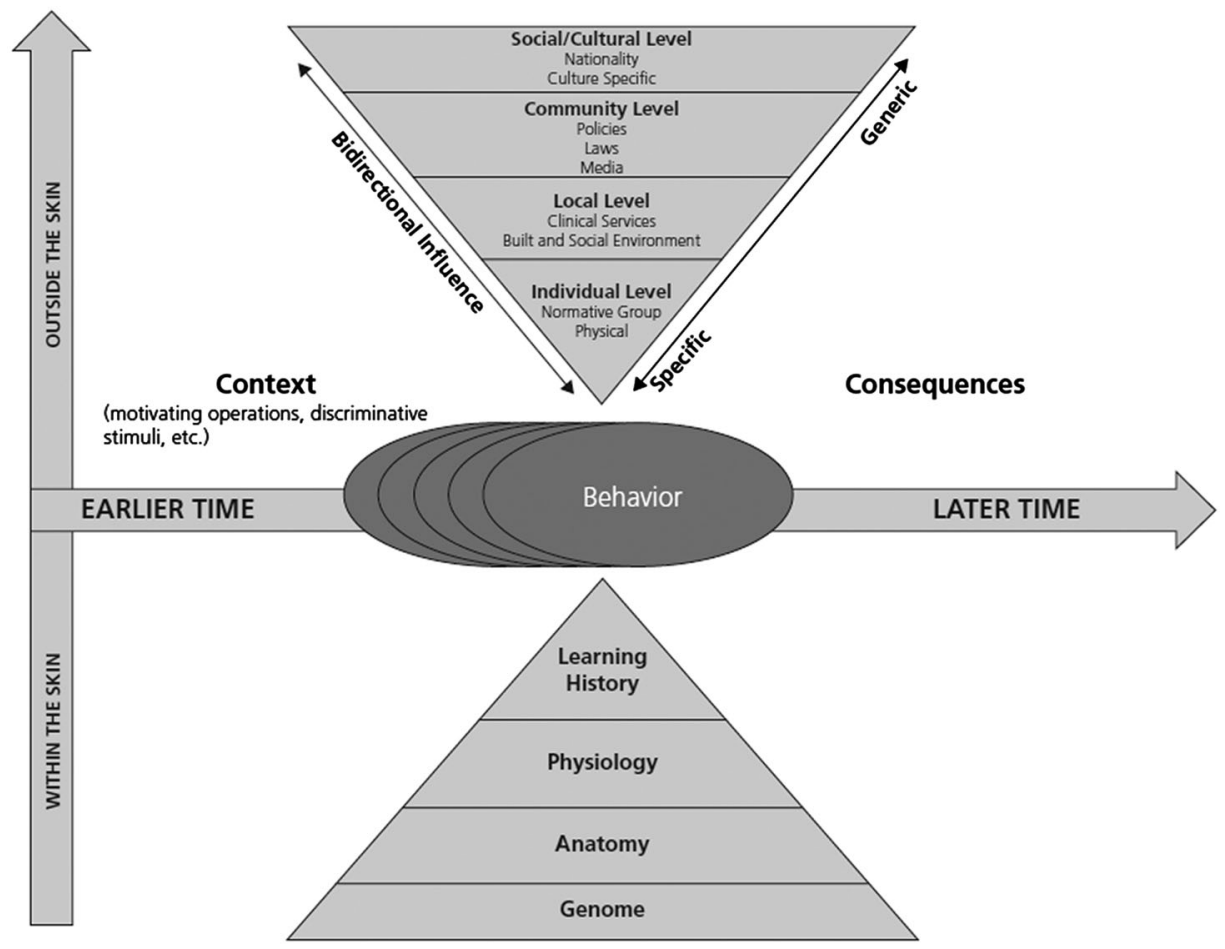

Figure 1. BEM by Hovell et al. (2009). Image used with permission of the authors.

between antecedents (A) or context, behaviour (B) and its consequents $(C)$. For that reason, this approach is also known as the $A B C$ model. According to the $B E M$, an individual's behaviour is the product of their genome, anatomy, physiology and learning history (lower triangle), i.e., of factors within and outside the skin (vertical arrow), altering as a function of consequences (horizontal arrow), all in a constellation of wider contingencies involving other individuals (upper triangle). This process of selection of behaviours through consequences, analogous to that of the origin of new species, accounts for the shaping and maintenance of individual behaviour, as well as for the evolution of cultural practices (Skinner, 1981).

Although $A B C$ formulations have traditionally focused on individual behaviour, the same approach has been taken to study groups or populations by focusing on their products or practices. Two key concepts in the analysis of cultural practices are metacontingencies and macrocontingencies. In many ways similar to an individual contingency, a metacontingency is the unit of analysis encompassing a cultural practice and refers to the 'contingent relation between (1) recurring interlocking behavioural contingencies (IBCs) having an aggregate product and (2) selecting environmental events or conditions' (Glenn et al., 2016, p. 13). Taking the example of the automobile industry: (1) includes some constants (e.g., types of jobs to be done, factory design for assembly) and more dynamic and fluid elements (e.g., specific ways in which individual supervisors respond to workers, how pay relates to work performance, co-workers' verbal and non-verbal responses to management as well as to objects involved in the task), as well as an aggregate product which is the number and quality of cars produced; (2) are those who buy cars, and who, by doing so, reinforce the set of IBCs in (1) (Glenn, 1988, p. 168). In turn, the aggregate behaviour of participants is constrained by its physical, institutional and legal environments, affecting each other bidirectionally (e.g., when different car manufacturers compete to increase sales, or governments impose restrictions on $\mathrm{CO}_{2}$ emissions).

On the other hand, a macrocontingency consists of a cumulative effect of social significance as a result of individual reinforcement and metacontingencies (Glenn et al., 2016, p. 19). Of relevance to 
AST, air pollution and global warming are partly attributable to the use of motorised transportation, both by individuals and by groups of individuals (e.g., buses). The study of cultural contingencies is challenging for a number of reasons, mainly practical, but this conceptual analysis is supported by empirical data (Ortu, Becker, Woelz, \& Glenn, 2012; Vichi, Andery, \& Glenn, 2009).

Understanding all levels and their interactions may be required to fully comprehend or engineer sustained health-related practices, but one may focus on a given level for an account at that level of analysis (Hovell et al., 2009). This is particularly relevant when researchers have little power to affect policies or other higher-level influences. For that reason, this article concentrates on individual contingencies in which parents and children are the main actors, irrespective of the metacontingencies in which they are embedded.

\section{View of behaviour}

Behaviour is defined as everything that an individual does, at the overt and covert levels, including motor, physiological, verbal, emotional and perceptual (e.g., seeing or hearing) behaviour (Skinner, 1953). Taking the example of self-efficacy, a possible non-cognitive account is that people often make statements about their future behaviour, silently or loudly, and the consequences of those predictions have established a response class that includes both the statements and their actual behaviour (Biglan, 1987). 'Perception' is a term that behaviour analysts typically use in the context of sensory perception, or how individuals sense the visual, auditory or otherwise sensorial stimuli around them (e.g., Reynolds \& Hayes, 2017). It is unclear how similar this is to 'perception' of safety of an environment (e.g., Pont et al., 2011), which may be referring to a process of discrimination, i.e., responding to some stimuli but not to others (Zentall, Galizio, \& Critchfield, 2002). For example, parents are likely to be more protective of their child walking to school, either because of personal experience or due to what they have heard from others, but less vigilant if the child is playing in their own garden.

Experimental demonstrations of covert behaviour are challenging, but in the absence of such evidence, alternative contextualistic interpretations of psychological concepts are possible (Machado \& Silva, 2007; Skinner, 1945). Occasionally, behaviour-analytic literature refers to constructs which may describe forms of covert behaviour, but these are treated as additional dependent variables (Chiesa, 1994, p. 171) and are sometimes used in empirical studies to 'validate' and predict overt behaviour (e.g., Hastings \& Symes, 2002).

Behaviour analysts recognise that experience changes the physiology of the organism and that these changes mediate the effects of subsequent environmental events, but because those physiological changes and private events cannot be directly manipulated, only the environmental conditions in which behaviour occurs are viewed as causes (Anderson, Hawkins, \& Scotti, 1998, p. 161). This environment corresponds to the people, objects, and events - stimuli - currently present in one's immediate surroundings that impinge on one's sense receptors and that can affect behaviour. When behaviour changes as a result of alterations in the environment, we speak of conditioning (Pierce \& Cheney, 2004). Two conditioning processes are the heart of the BEM: respondent conditioning and operant conditioning.

\section{Respondent conditioning}

The group of behaviours studied by respondent conditioning - respondent behaviours - are involuntary and automatic responses such as reflexes, glandular responses and what we call emotions, presumably under the control of autonomic nervous system (Nord \& Peter, 1980). Respondent conditioning occurs when a meaningless or neutral stimulus is paired with an unconditioned stimulus, which naturally causes respondent behaviour, acquiring the capacity to elicit a similar response (Pavlov, 1927). For example, people often react to situations which resemble an original context of 
trauma, even though these novel situations were not previously paired with pain (Arhin \& Thyer, 2004; Mineka \& Oehlberg, 2008).

Processes of respondent conditioning, although insufficient, may be worthwhile considering in AST. For example, parental concerns regarding 'stranger danger' and road safety have been identified as a potential barrier to children's outdoor physical activity, including active travel (Carver, Timperio, \& Crawford, 2008). Yet most children in developed countries will never experience any significant 'stranger' or traffic danger during their school years (CAPT, 2013). Nonetheless, media coverage of cases of child abduction or murder exacerbates parental fears and anxieties (Zubrick et al., 2010). Thus, depictions of these rare cases on TV, newspapers and on the Internet become strong conditioned aversive stimuli in parents' environments, which can undermine AST promotion efforts. Social marketing strategies, civic journalism, and particularly more reporting of positive news of how families enjoy and benefit from AST (Zubrick et al., 2010), as well as features of the journey to school (e.g., presence of other children), could elicit more positive feelings and predispose more parents to allow their children to walk or cycle to school.

\section{Operant conditioning}

Behaviours such as walking, eating or talking are the function of a larger number of variables. In these cases, people operate on their surrounding environment and in doing so encounter special kinds of stimuli - consequences - which alter the probability of repeating that behaviour in the future. Consequences that increase the probability of (or strengthen) future similar behaviour are reinforcers; consequences that decrease the likelihood of (or weaken) future behaviour are aversive stimuli or punishers. Two behaviours may be topographically identical (e.g., a single eye blink) but functionally different, for example, when one blinks due to eye irritation (respondent) or winks at a friend in a bar (operant).

Reinforcers and punishers can both be positive or negative, depending on whether behaviour is strengthened or weakened by the addition or removal of a stimulus, respectively (Skinner, 1953). In casual discourse, positive reinforcement is usually implied by what we 'want' or 'like' to do, and negative reinforcement by the things that we 'have to do'. Consequences correlate typically with other aspects of the environment or situation, which is often referred to contingencies of reinforcement (or punishment), or as antecedents-behaviour-consequents (ABCs) relationships (Kazdin, 2012). Anything that alters the effectiveness of a consequence is called a motivating operation, including the extent to which the individual has gone with or without the consequence, known as satiation and deprivation, respectively (Laraway, Snycerski, Michael, \& Poling, 2003).

Various examples of $A B C$ formulations are found in health promotion research. For example, in physical activity interventions (Sallis \& Owen, 1999), changing antecedents included planning specific times and locations for PA, keeping running shoes in the car, and living near attractive facilities; changing behaviour by altering the consequences included socialising with others whilst exercising, and monetary incentives for active travel to work. The authors stressed that interventions needed not only to administrate reinforcers, but also to consider ways of removing or reducing punishers, e.g., discomfort during exertion, or being laughed at because of poor sports skills. Feedback on performance is another important consequence-based strategy which has proven successful in increasing physical activity in older adults (O'Brien et al., 2015).

Table 2 shows a non-exhaustive list of potential antecedents and potential reinforcers for AST, and also potential reinforcers for motorised travel. The list is suggested by the existing, mainly correlational, literature, and should be subject to further investigation. Antecedents are classed according to the various levels of the BEM. These include individual level (normative group and physical), local level (clinical services, built and social environment), community level (policies, laws, media) and social/cultural level (nationality and culture specific). For convenience, local and community levels are presented together (e.g., parks and recreation facilities exist locally, but often reflect national policies). 
Most literature suggests that parents are the primary decision-makers of their child's travel mode (s) to school (Davison, Werder, \& Lawson, 2008; Faulkner, Richichi, Buliung, Fusco, \& Moola, 2010; Panter et al., 2008) but their decision may be influenced by their child's preferences and age (Pont et al., 2011). Thus, an ABC assessment of school travel mode is likely to benefit from attending to both perspectives. $A B C$ assessments have been traditionally carried out at the individual level (Cole \& Bonem, 2000). Since we are taking a generic perspective, rather than an individual focus, potential antecedents and consequents for AST are presented together, as previously reported in other contexts of health promotion (Adams, Norman, Hovell, Sallis, \& Patrick, 2009; Gielen \& Sleet, 2003).

Antecedents correspond to stimuli which increase opportunities for reinforcement. As such, they increase the likelihood of behaviour, but always in combination with other contextual factors, or conditions favouring engagement in alternative activities, a principle known as the Matching Law (Herrnstein, 1961). Indeed, assessment of competing contingencies of reinforcement is acknowledged to be one of the most important, but also challenging, tasks in behaviour change interventions (Barnett, Bell, \& Carey, 2002). It has been noted that 'children's environments have many well-established, competing contingencies of reinforcement, such as the enjoyment contingent on play behaviour. If left to chance, these may compete with the development of important academic or interpersonal skills, to the child's detriment' (Follette, Linnerooth, \& Ruckstuhl Jr, 2001, pp. 127-128). Reinforcers administered contingently upon desired behaviour, such as praise, edibles or small material prizes, can increase the reinforcing value of the targeted behaviour over others.

Some correlates such as gender of the child or ethnic background are omitted from our analysis because their effects are likely to be indirect. For example, parents are often more protective towards girls (e.g., De Meester, Van Dyck, De Bourdeaudhuij, \& Cardon, 2014) and safety concerns are reported more frequently for girls than for boys (Evenson et al., 2006). For many parents, protective behaviour towards girls may, societally, be more accepted (i.e., reinforced), or less resisted (i.e., punished), than towards boys (e.g., Mayhew, Uprichard, Beresford, Ridge, \& Bradshaw, 2004). In some social groups, car ownership, and its daily use, is more common, and those who drive their children to school may be less often subjected to unwanted attention than parents from other backgrounds who do the same (e.g., Eyre, Duncan, Birch, \& Cox, 2013). Distance, a key determinant of AST, is also likely to be a moderator for other variables (e.g., house location), rather than being itself amenable to direct manipulation.

Because the studies referenced on Table 2 are from a non-behaviour-analytic literature, there is a variable degree of clarity and specificity as to what each of the variables mean, e.g., 'social encouragement and approval for active lifestyles' and 'equality and environmental awareness'. These may refer both to antecedents (e.g., laws, behaviour of other people) and to consequences (e.g., approval from others contingent upon behaviour). In a more comprehensive $A B C$ analysis, punishers for AST such as criminality or road hazards should be covered so that strategies to minimise their impact can be devised. Table 2 suggests three ways of tackling school travel behaviour: by changing the antecedents, by introducing (or strengthening) reinforcers for AST, and/or by withdrawing reinforcers for motorised travel. This perspective and these techniques are largely consistent with the 'nudging approach' adopted by the Behavioural Insights Team, a UK government institution dedicated to the application of behavioural science (BIT, 2016a). Withdrawing reinforcers for motorised travel, especially if combined with the reinforcement of AST, is likely to be more effective and acceptable than introducing punishing consequences for car use, for example fines (Lerman \& Vorndran, 2002). Although some strategies are unequivocally punitive (e.g., fines), in others the distinction between reinforcement removal and punishment is less clear. For instance, narrowing a road constitutes a loss of the conditions available to motorists to increase their speed rather than the administration of a punishment, yet it is likely to be just as off-putting to car users by making driving less convenient. 


\section{Potential antecedents for AST}

- No car available (Pont et al., 2009; Sirard \& Slater, 2008)

- Lower socioeconomic status (e.g., less money available) (Davison et al 2008; Pont et al., 2009; Sirard \& Slater, 2008) (Panter, Corder, Griffin, Jones, \& van Sluijs, 2013)

- Independent mobility (allowed to be out alone) (Davison et al., 2008)

- Parents currently walk or cycle to work (Davison et al., 2008; Van Kann, Kremers, de Vries, de Vries, \& Jansen, 2016)

- Parents encourage AST and walking (Sirard \& Slater, 2008) (Panter et al 2010)

- Parents encourage PA and social interaction during AST (Davison et al., 2008)

- Encouragement from others (Davison et al., 2008)

- AST more convenient, time available ( Panter et al., 2013) (Trapp et al., 2012)

- Other children in the area walk/cycle to school (Davison et al., 2008)

- Shorter distance (Davison et al., 2008; Panter et al., 2008; Pont et al., 2009; Saelens \& Handy, 2008; Sirard \& Slater, 2008; Wong, Faulkner, \& Buliung 2011)

- State-funded schools (Davison et al., 2008; Sirard \& Slater, 2008)

- Non-religiously affiliated (Davison et al., 2008)

- Schools that encourage physical education and active travel initiatives (Sirard \& Slater, 2008)

- Proximity to shops ( Panter et al., 2008; Sirard \& Slater, 2008)

- Walkability index (calculated by residential density, retail floor area ratio intersection density and land use mix) (Davison et al., 2008; Saelens \& Handy, 2008; Sirard \& Pate, 2001)

- Urban areas (Davison et al., 2008; Sirard, Alhassan, Spencer, \& Robinson, 2008)

- Pavements, cycle lanes and cycle parking facilities (Davison et al., 2008 Pont et al., 2009; Saelens \& Handy, 2008; Sirard \& Slater, 2008)

- Parks and recreation facilities (Pont et al., 2009)

- Aesthetics and more windows facing the street (Sirard \& Slater, 2008)

- Good weather (Fraser \& Lock, 2011)

- Diversity of views (Pikora, Giles-Corti, Bull, Jamrozik, \& Donovan, 2003)

- Road and area safety (Davison et al., 2008; Panter et al., 2008; Pont et al. 2009; Sirard \& Slater, 2008)

- Social encouragement and approval for active lifestyles (McMillan, Day,

Boarnet, Alfonzo, \& Anderson, 2006)

- Equality and environmental awareness (Garrard, 2011)
Immediate:

Potential reinforcers for AST

- Being active/fit (Fusco, Faulkner, Moola, Buliung, \& Richichi, 2013) (Davison, Davison, Reed, Halden, \& Dillon, 2003) (Kirby \& Inchley, 2009)

Having fun (Mitchell, Kearns, \& Collins, 2007) (Hunter, Silva, Reynolds, Bird, \& Fox, 2015) (Romero, 2015)

- Listening to music (Kirby \& Inchley, 2009)

- Gives energy (Mitchell et al., 2007)

- Interesting things to look at/nature (Mitchell et al. 2007) (Fusco et al., 2013)

- Interaction with other children/make friends (Davison et al., 2008) (Kirby \& Inchley, 2009) (Fusco et al., 2013)

- Cycling is ' cool' (attention and approval from others) (Trapp et al., 2011) (Baslington, 2009)

- Feeling the sun (Mitchell et al, 2007)

- Breathing fresh air (Kirby \& Inchley, 2009)

- Faster than walking (cycling) (Mitchell et al., 2007)

- Feeling more alert at school (Mitchell et al, 2007) (Kirby \& Inchley, 2009)

- Save money (Kirby \& Inchley, 2009)

Approval from parents and others (Sirar (Panter et al. 2010)

Non-naturally occurring:

- Rewards/incentives (Kirby \& Inchley, 2009) (Davies, 2012)

- Raising funds for charity (Hunter et al., 2015)

Delayed:

Better health (Fusco et al., 2013; Kirby \& Inchley, 2009)

- - Benefits to the environment (Davison et al, 2003) (Kirby \& Inchley, 2009)
Potential reinforcers for motorised travel

Immediate:

- Time saved (convenience) (Faulkner et al., 2010)

- Less effort (Faulkner et al., 2010)

- Safer (Fyhri et al., 2011)

- Having a car is 'cool' (attention and approval from others) (Lorenc, Brunton, Oliver, Oliver, \& Oakley, 2008)

- Listening to music (Romero, 2015)

- Cheaper (bus) (Pooley et al., 2010)

- Interaction with friends (bus) (Mitchell et al., 2007)

- Good view from the bus (Mitchell et al. 2007)

- Avoid bullies (Ahlport, Linnan, Vaughn, Evenson, \& Ward, 2008)

- Avoid cold/rain (Kirby \& Inchley, 2009)

- Avoid carrying bag (Kirby \& Inchley, 2009)

- Avoid exposure to pollution (Pooley et al., 2010)

Delayed:

- Benefits to the environment (bus compared to car) (Baslington, 2009) 
Some potential reinforcers are long-deferred or inconspicuous, such as 'being fit' or reducing air pollution. Rather than resulting from a direct exposure to contingencies, people may be behaving mainly because of contingencies which are mediated be other people.

\section{Rule-governed behaviour}

A distinction is made between contingency-shaped behaviour, which is the result of direct contact with contingencies of reinforcement, and rule-governed behaviour, which is under the control of descriptions of reinforcement contingencies such as rules (Catania, Shimoff, \& Matthews, 1989; Skinner, 1957). In this context, rules can refer both to simple verbal prompts or more complex descriptions or instructions, and depend on the verbal ability of the listener (and speaker). Parents who engage in AST on the grounds of trying to reduce air pollution may do so not necessarily due to immediate or obvious consequences, but because following the advice of experts has paid off in other situations. Like rule-following, imitation is also believed to occur, at least in part, because we are often reinforced for doing as others do (Masia \& Chase, 1997). The notion of stating norms and encouraging people to comply is also in line with the 'nudge' agenda (e.g., BIT, 2016b).

Experimental data suggest that rule-governed behaviour may reduce an individual's sensitivity to actual (non-rule-governed) contingencies (Ghaderi, 2006; Hayes, Brownstein, Zettle, Rosenfarb, \& Korn, 1986). Often both sorts of behaviour are thought to co-exist (Hastings \& Brown, 2000). Once language is acquired in a verbal community, self-talk may 'bridge the gap' between environment and (overt) behaviour. For example, by providing instructions to themselves, individuals make target actions less ambiguous and improve their performance, as it seems to be the case in athletes (Hardy, 2006, p. 91). Similarly, goal setting can be seen as verbal stimuli specifying a performance which would otherwise be less clear, although in practice the relation between goal specificity and the effectiveness of goal setting interventions is not always straightforward (McEwan et al., 2016).

\section{Schedules of reinforcement in health behaviour change}

One important property of reinforcers is their schedule, i.e., the conditions under which reinforcement occurs. Although some behaviours are reinforced invariably at each occurrence (e.g., drinking $\rightarrow$ quenching thirst), most behaviours are only reinforced intermittently (Ferster \& Skinner, 1957). For example, it is likely that children will only 'have fun' during some journeys to school, and that multiple active trips to school are required to notice an effect on 'fitness'. Behaviour acquired through intermittent reinforcement is more resistant to extinction than that instigated after a continuous schedule (e.g., Horsley, Osborne, Norman, \& Wells, 2012; Nevin, 2012).

Schedules of reinforcement are extensively used to change health behaviour by introducing nonnaturally occurring reinforcers intermittently. This is often easier than modifying social and infrastructural aspects of people's lives, or can be used as an addition to environmental changes. In a fixed-ratio schedule, a fixed number of responses are necessary for reinforcement, for example, in some coffee shops the 10th beverage is free. Under a variable-ratio schedule, the number of responses required for reinforcement varies unpredictably from one reinforcer to the next. Variable-ratio reward schemes have been applied to promote physical exercise in obese boys (Luca \& Holborn, 1992), in the management of problem behaviour and acquisition of communication in children (Kelley, Lerman, \& Camp, 2002), or to increase AIDS-preventing behaviour (Haug \& Sorensen, 2006). Of special relevance to this project, in the Boltage programme (US) children who rode their bicycle to school were entered into a weekly prize draw (\$10) (Cuffe, Harbaugh, Lindo, Musto, \& Waddell, 2012).

Some data support the potential of incentives to promote health behaviours in children and youth, using fixed and variable-ratio schedules of reinforcement (Jensen, Hartmann, de Mul, Schuit, \& Brug, 2011; Kavanagh, Oakley, Harden, Trouton, \& Powell, 2011). Different schedules may be combined at the same time, and the amount and type of reinforcer may vary throughout the 
intervention. On the downside, reinforcement schedules do not always predict behaviour as expected (Barkley, 2013). Strategies such as loyalty cards or lotteries often work but behaviour change tends to be of short duration once the incentive is discontinued (Strohacker, Galarraga, \& Williams, 2014). To increase the potential for behaviour maintenance, it is commonly accepted that rewards need: (a) to continue; (b) to be withdrawn gradually rather than suddenly; or (c) to be applied using an intermittent schedule rather than a continuous schedule (Johnston, 2016). Indeed, fixed-ratio schedules are more effective during initiation of the behaviour, while a variable-ratio schedule is best in maintaining behaviour over time (Burns et al., 2012).

Even when behaviour change is short-lived, incentive approaches may be cost-effective (Dallat, Hunter, Tully, Cairns, \& Kee, 2013; Hanewinkel \& Isensee, 2012). In the Boltage child cycling promotion programme, a $16 \%$ increase in rides was limited to draw periods and the following weeks, but only six cents was spent per child (Cuffe et al., 2012). Compared to other interventions (e.g., infrastructural), incentive schemes are low-cost, can be delivered quickly and often do not require any particular expertise. With lotteries, one prize often suffices to motivate an entire group. All of these factors are likely to appeal to policy-makers, especially when funding is limited and/or modifying transport infrastructure is impracticable or strongly resisted. In the case of an AST incentive scheme, the encouragement of teachers and parents, as well as having peers taking part, may provide additional reinforcement for participants even in the absence of any prizes won.

\section{Strengths and limitations of the BEM}

Similar to other ecological models, one of the main strengths of the BEM is the recognition of multiple levels and sources of influence on AST. This increases the number and options of potential interventions substantially. Other advantages of the BEM are its concern for conceptual clarity and its emphasis on behaviour and on observable interactions between individuals and their surroundings. Other existing ecological models have been criticised for failing to explain how the environment exerts its effects on people's behaviour (Nelson, 2007); contingencies of reinforcement may help answer the question. A focus on overt behaviour has the advantage of directing attention to its interaction with external variables, which are the only ones amenable to direct manipulation and measurement by behavioural researchers (Chiesa, 1994). This makes the BEM more practical, parsimonious and, to some extent, more testable than other models. On the issue of behaviour maintenance, often unaddressed by existing models, the BEM suggests the need for introducing some level of reinforcement over time, or making it more conspicuous, and modifying other aspects of the child's environment (Table 2). In addition, the BEM directs attention to the antecedents and reinforcers of car use (e.g., convenience), which may explain why people choose to drive and their difficulty in maintaining AST over time.

Many of the limitations of the BEM apply to other models. In any ecological approach, contingencies at the societal level are very difficult to test. Because of its strong reliance on laboratory research, behavioural principles do not always predict or work as expected due to the wider range of uncontrolled variables in everyday life. At a more individual level, some contingencies of reinforcement are difficult to spot, especially if reinforcement occurs intermittently. Even if specific antecedents or reinforcers can be identified, these may not be possible to change (e.g., weather, lack of financial resources). The behaviour-analytic language which is characteristic of the BEM contrasts with that of more popular models and poses a challenge to audiences who are unfamiliar with it.

\section{Conclusion}

To the best of our knowledge, this is the first time that AST is presented having the BEM as conceptual basis. It is, however, worth noting that techniques of classical and operant conditioning, which constitute the main theoretical body of the BEM, are common in weight management programmes in contexts such as the National Health Service in the UK (Newson \& Flint, 2011), suggesting their deliverability in behaviour change settings. 
Promoting AST and other health behaviours is challenging in part because their positive effects are inconspicuous or long-deferred. Making the journey to school fun and more immediately rewarding in other ways could balance out the reinforcers of motorised travel, such as convenience and comfort. Furthermore, there are practical, ethical and economic difficulties in modifying many of the social and non-social (e.g., infrastructural) conditions which determine the school travel choices of parents and children. These constraints, coupled with the increasingly tight budgets allocated to intervention delivery and research, suggest that an incentive scheme is an affordable way to increase the reinforcing value of the school commute by applying key principles of operant behaviour change upon which the BEM was developed. Often described as fun by young people, incentive schemes can be implemented easily in a variety of contexts of health promotion. Cash rewards may be of appeal to those in socioeconomic disadvantage who suffer disproportionately the burden of disease and whose engagement in research is often challenging, which offers, in the absence of more structural solutions, a potential to tackle health inequalities.

In this article, we have questioned how existing AST formulations have, in practice, informed the development and evaluation of AST interventions; we have addressed their frequent lack of attention to the maintenance of behaviour and we have proposed the BEM as a guide for this area of research. By doing so, we have suggested a focus on the interaction between behaviour and the contexts in which it occurs, and have drawn particular attention to the role of consequences in the acquisition and maintenance of behaviour. In the absence of controlled studies, this task is often interpretative rather than underpinned by robust evidence. Yet behaviour analysis, upon which the BEM has been developed, has a long tradition in psychology and has been fruitful in areas such as psychotherapy and organisational behaviour. In the spirit of maintaining that tradition alive, we herein attempted to extend this approach to AST and show how an analysis of reinforcement contingencies, of both individuals and groups, makes the BEM a more promising model than previous ones. We hope this article will lead to similar analyses in AST and in other areas of behavioural science, in the interest of continuing to improve our ability to predict and control health behaviour.

\section{Acknowledgements}

The authors thank a number of individuals who provided helpful comments during the writing of this manuscript, including Dr Vera Araujo-Soares during the writing of the first draft, and Professor Armando Machado and Professor Melbourne Hovell during the writing of the revised version. We are also grateful to Dr Joana Almeida for her technical support.

\section{Disclosure statement}

No potential conflict of interest was reported by the authors.

\section{Funding}

This work was supported by a Sir James Knott Fellowship awarded to the first author; this fellowship is bestowed to the Institute for Sustainability at Newcastle University.

\section{References}

AAAS. (2011). Q \& A on evolution and intelligent design. Washington, DC: Author.

Active Healthy Kids Australia. (2015). The road less travelled: The 2015 active healthy kids Australia progress report card on active transport for children and young people. Adelaide: Author.

Adams, M. A., Hovell, M. F., Irvin, V., Sallis, J. F., Coleman, K. J., \& Liles, S. (2006). Promoting stair use by modeling: An experimental application of the behavioral ecological model. American Journal of Health Promotion, 21(2), $101-109$.

Adams, M. A., Norman, G. J., Hovell, M. F., Sallis, J. F., \& Patrick, K. (2009). Reconceptualizing decisional balance in an adolescent sun protection intervention: Mediating effects and theoretical interpretations. Health Psychology, $28(2), 217$.

Ahlport, K. N., Linnan, L., Vaughn, A., Evenson, K. R., \& Ward, D. S. (2008). Barriers to and facilitators of walking and bicycling to school: Formative results from the non-motorized travel study. Health Education \& Behavior, 35(2), $221-244$. 
Ajzen, I. (2011). Theory of planned behavior. Handbook of Theories of Social Psychology, 1, 438.

Anderson, C. M., Hawkins, R. P., \& Scotti, J. R. (1998). Private events in behavior analysis: Conceptual basis and clinical relevance. Behavior Therapy, 28(1), 157-179.

Arhin, A., \& Thyer, B. A. (2004). The causes of racial prejudice: A behavior analytic perspective. The Psychology of Prejudice and Discrimination, 1, 1-19.

Bandura, A. (1989). Human agency in social cognitive theory. American Psychologist, 44(9), 1175.

Barkley, R. A. (2013). The problem of stimulus control and rule-governed behavior in attention deficit disorder with hyperactivity. Attention Deficit Disorder, 4, 203-234.

Barnett, D. W., Bell, S. H., \& Carey, K. T. (2002). Designing preschool interventions: A practitioner's guide. New York, NY: Guilford Press.

Baslington, H. (2009). Children's perceptions of and attitudes towards, transport modes: Why a vehicle for change is long overdue. Children's Geographies, 7(3), 305-322.

Biglan, A. (1987). A behavior-analytic critique of Bandura's self-efficacy theory. The Behavior Analyst, 10(1), 1.

BIT. (2016a). The behavioural insights team. Retrieved from http://www.behaviouralinsights.co.uk/

BIT. (2016b). The behavioural insights team. Applying behavioural insights to legacy giving. Retrieved from http://www. behaviouralinsights.co.uk/uncategorized/applying-behavioural-insights-to-legacy-giving/

Bronfenbrenner, U. (1979). The ecology of human development: Experiments by nature and design. Cambridge, MA: Harvard University.

Burns, R. J., Donovan, A. S., Ackermann, R. T., Finch, E. A., Rothman, A. J., \& Jeffery, R. W. (2012). A theoretically grounded systematic review of material incentives for weight loss: Implications for interventions. Annals of Behavioral Medicine, 44(3), 375-388.

CAPT. (2013). Child deaths from road traffic accidents. The Child Accident Prevention Trust. Retrieved from http:// makingthelink.net/child-deaths-road-traffic-accidents

Carver, A., Timperio, A., \& Crawford, D. (2008). Playing it safe: The influence of neighbourhood safety on children's physical activity - A review. Health \& Place, 14(2), 217-227.

Catania, A. C., Shimoff, E., \& Matthews, B. A. (1989). An experimental analysis of rule-governed behavior. In S. C. Hayes (Ed.), Rule-governed behavior: Cognition, contingencies, and instructional control (pp. 119-150). New York: Plenum.

Chiesa, M. (1994). Radical behaviorism: The philosophy and the science. Boston, MA: Authors Cooperative.

Chillon, P., Evenson, K. R., Vaughn, A., \& Ward, D. S. (2011). A systematic review of interventions for promoting active transportation to school. International Journal of Behavioral Nutrition and Physical Activity, 8. doi:10.1186/1479-5868-8-10

Cole, M. L., \& Bonem, M. K. (2000). The ABC's of smoking cessation: Using behavioral strategies to help undergraduates stop smoking. The Behavior Analyst Today, 1(4), 89.

Craig, P., Dieppe, P., Macintyre, S., Michie, S., Nazareth, I., \& Petticrew, M. (2013). Developing and evaluating complex interventions: The new medical research council guidance. International Journal of Nursing Studies, 50(5), 587-592.

Cuffe, H. E., Harbaugh, W. T., Lindo, J. M., Musto, G., \& Waddell, G. R. (2012). Evidence on the efficacy of school-based incentives for healthy living. Economics of Education Review, 31(6), 1028-1036. doi:10.1016/j.econedurev.2012.07.001

Dallat, M. A. T., Hunter, R. F., Tully, M. A., Cairns, K. J., \& Kee, F. (2013). A lesson in business: Cost-effectiveness analysis of a novel financial incentive intervention for increasing physical activity in the workplace. BMC Public Health, $13(1), 953$.

Davies, N. (2012). What are the ingredients of successful travel behavioural change campaigns? Transport Policy, 24, 19-29.

Davison, K. K., Werder, J. L., \& Lawson, C. T. (2008). Peer reviewed: Children's active commuting to school: Current knowledge and future directions. Preventing Chronic Disease, 5(3). Retrieved from https://www.ncbi.nlm.nih.gov/pmc/ articles/PMC2483568/

Davison, P., Davison, P., Reed, N., Halden, D., \& Dillon, J. (2003). Children's attitudes to sustainable transport. Edinburgh: Scottish Executive, Social Research.

De Meester, F., Van Dyck, D., De Bourdeaudhuij, I., \& Cardon, G. (2014). Parental perceived neighborhood attributes: Associations with active transport and physical activity among 10-12 year old children and the mediating role of independent mobility. BMC Public Health, 14(1), 631.

de Nazelle, A., Nieuwenhuijsen, M. J., Antó, J. M., Brauer, M., Briggs, D., Braun-Fahrlander, C., ... Fruin, S. (2011). Improving health through policies that promote active travel: A review of evidence to support integrated health impact assessment. Environment International, 37(4), 766-777.

DfT. (2016). National Travel Survey: 2015. Trips to school by main mode, trip length and age: England. London: Author.

Dresler-Hawke, E., \& Whitehead, D. (2009). The behavioral ecological model as a framework for school-based anti-bullying health promotion interventions. The Journal of School Nursing, 25(3), 195-204.

Evenson, K. R., Birnbaum, A. S., Bedimo-Rung, A. L., Sallis, J. F., Voorhees, C. C., Ring, K., \& Elder, J. P. (2006). Girls' perception of physical environmental factors and transportation: Reliability and association with physical activity and active transport to school. International Journal of Behavioral Nutrition and Physical Activity, 3(1), 28.

Eyre, E. L. J., Duncan, M. J., Birch, S. L., \& Cox, V. (2013). Environmental and school influences on physical activity in South Asian children from low socio-economic backgrounds: A qualitative study. Journal of Child Health Care, 19(3), 345-358.

Faulkner, G. E. J., Richichi, V., Buliung, R. N., Fusco, C., \& Moola, F. (2010). What's 'quickest and easiest?' Parental decision making about school trip mode. The International Journal of Behavioral Nutrition and Physical Activity, 7, 62. 
Ferster, C. B., \& Skinner, B. F. (1957). Schedules of reinforcement. New York: Appleton-Century-Crofts.

Fleury, J., \& Sidani, S. (2012). Using theory to guide intervention research. In B. Mazurek Melnyk \& D. Morrison-Beedy (Eds.), Intervention research: Designing, conducting, analyzing and funding (pp. 11-36). New York: Springer Publishing Company.

Follette, W. C., Linnerooth, P. J. N., \& Ruckstuhl Jr, L. E. (2001). Positive psychology: A clinical behavior analytic perspective. Journal of Humanistic Psychology, 41(1), 102-134.

Fraser, S. D. S., \& Lock, K. (2011). Cycling for transport and public health: A systematic review of the effect of the environment on cycling. European Journal of Public Health, 21(6), 738-743. doi:10.1093/eurpub/ckq145

Fusco, C., Faulkner, G., Moola, F., Buliung, R., \& Richichi, V. (2013). Urban school travel: Exploring children's qualitative narratives about their trip to school. Children Youth and Environments, 23(3), 1-23.

Fyhri, A., Hjorthol, R., Mackett, R. L., Fotel, T. N., \& Kytta, M. (2011). Children's active travel and independent mobility in four countries: Development, social contributing trends and measures. Transport Policy, 18(5), 703-710. doi:10.1016/j. tranpol.2011.01.005

Garrard, J. (2011). Active travel to school: Literature review. Canberra: ACT Government.

Ghaderi, A. (2006). Does individualization matter? A randomized trial of standardized (focused) versus individualized (broad) cognitive behavior therapy for bulimia nervosa. Behaviour Research and Therapy, 44(2), 273-288.

Gielen, A. C., \& Sleet, D. (2003). Application of behavior-change theories and methods to injury prevention. Epidemiologic Reviews, 25(1), 65-76.

Glenn, S. S. (1988). Contingencies and metacontingencies: Toward a synthesis of behavior analysis and cultural materialism. The Behavior Analyst, 11(2), 161.

Glenn, S. S., Malott, M. E., Andery, M. A. P. A., Benvenuti, M., Houmanfar, R. A., Sandaker, I., .. Vasconcelos, L. A. (2016). Toward consistent terminology in a behaviorist approach to cultural analysis. Behavior and Social Issues, $25,11-27$.

Hallal, P. C., Andersen, L. B., Bull, F. C., Guthold, R., Haskell, W., \& Ekelund, U. (2012). Global physical activity levels: Surveillance progress, pitfalls, and prospects. The Lancet, 380(9838), 247-257.

Hanewinkel, R., \& Isensee, B. (2012). Meta-analysis on the effects of the smoke-free class competition on smoking prevention in adolescents. European Addiction Research, 18(3), 110.

Hardy, J. (2006). Speaking clearly: A critical review of the self-talk literature. Psychology of Sport and Exercise, 7(1), 81-97. doi:10.1016/j.psychsport.2005.04.002

Hastings, R. P., \& Brown, T. (2000). Functional assessment and challenging behaviors: Some future directions. Journal of the Association for Persons with Severe Handicaps, 25(4), 229-240.

Hastings, R. P., \& Symes, M. D. (2002). Early intensive behavioral intervention for children with autism: Parental therapeutic self-efficacy. Research in Developmental Disabilities, 23(5), 332-341.

Haug, N. A., \& Sorensen, J. L. (2006). Contingency management interventions for HIV-related behaviors. Current HIV/AIDS Reports, 3(4), 154-159.

Hayes, S. C., \& Brownstein, A. J. (1986). Mentalism, behavior-behavior relations, and a behavior-analytic view of the purposes of science. The Behavior Analyst, 9(2), 175.

Hayes, S. C., Brownstein, A. J., Zettle, R. D., Rosenfarb, I., \& Korn, Z. (1986). Rule-governed behavior and sensitivity to changing consequences of responding. Journal of the Experimental Analysis of Behavior, 45(3), 237-256.

Herrnstein, R. J. (1961). Relative and absolute strength of response as a function of frequency of reinforcement. Journal of the Experimental Analysis of Behavior, 4(3), 267-272.

Hodgson, S., Namdeo, A., Araujo-Soares, V., \& Pless-Mulloli, T. (2012). Towards an interdisciplinary science of transport and health: A case study on school travel. Journal of Transport Geography, 21, 70-79.

Horsley, R. R., Osborne, M., Norman, C., \& Wells, T. (2012). High-frequency gamblers show increased resistance to extinction following partial reinforcement. Behavioural Brain Research, 229(2), 438-442.

Hovell, M. F., Wahlgren, D. R., \& Adams, M. A. (2009). The logical and empirical basis for the behavioral ecological model. Emerging Theories in Health Promotion Practice and Research, 2, 347-385.

Hunter, R. F., de Silva, D., Reynolds, V., Bird, W., \& Fox, K. R. (2015). International inter-school competition to encourage children to walk to school: A mixed methods feasibility study. BMC Research Notes, 8, 19-19. doi:10.1186/s13104-0140959-x

Jensen, J. D., Hartmann, H., de Mul, A., Schuit, A., \& Brug, J. (2011). Economic incentives and nutritional behavior of children in the school setting: A systematic review. Nutrition Reviews, 69(11), 660-674.

Johnston, M. (2016). What more can we learn from early learning theory? The contemporary relevance for behaviour change interventions. British Journal of Health Psychology, 21(1), 1-10.

Kavanagh, J., Oakley, A., Harden, A., Trouton, A., \& Powell, C. (2011). Are incentive schemes effective in changing young people's behaviour? A systematic review. Health Education Journal, 70(2), 192-205.

Kazdin, A. E. (2012). Behavior modification in applied settings. Long Grove, IL: Waveland Press.

Keil, F. C. (2006). Explanation and understanding. Annual Review of Psychology, 57, 227.

Kelley, M. E., Lerman, D. C., \& Camp, C. M. (2002). The effects of competing reinforcement schedules on the acquisition of functional communication. Journal of Applied Behavior Analysis, 35(1), 59-63.

Kirby, J., \& Inchley, J. (2009). Active travel to school: Views of 10-13 year old schoolchildren in Scotland. Health Education, 109(2), 169-183. 
Kwasnicka, D., Dombrowski, S. U., White, M., \& Sniehotta, F. (2016). Theoretical explanations for maintenance of behaviour change: a systematic review of behaviour theories. Health Psychology Review, 10(3), 277-296.

Laraway, S., Snycerski, S., Michael, J., \& Poling, A. (2003). Motivating operations and terms to describe them: Some further refinements. Journal of Applied Behavior Analysis, 36(3), 407-414.

Lerman, D. C., \& Vorndran, C. M. (2002). On the status of knowledge for using punishment: Implications for treating behavior disorders. Journal of Applied Behavior Analysis, 35(4), 431-464.

Lorenc, T., Brunton, G., Oliver, S., Oliver, K., \& Oakley, A. (2008). Attitudes to walking and cycling among children, young people and parents: A systematic review. Journal of Epidemiology and Community Health, 62(10), 852-857.

Lu, W., McKyer, E. L., Lee, C., Ory, M. G., Goodson, P., \& Wang, S. (2015). Children's active commuting to school: An interplay of self-efficacy, social economic disadvantage, and environmental characteristics. The International Journal of Behavioral Nutrition and Physical Activity, 12, 29. doi:10.1186/s12966-015-0190-8

Luca, R. V., \& Holborn, S. W. (1992). Effects of a variable-ratio reinforcement schedule with changing criteria on exercise in obese and nonobese boys. Journal of Applied Behavior Analysis, 25(3), 671-679.

Machado, A., \& Silva, F. J. (2007). Toward a richer view of the scientific method: The role of conceptual analysis. American Psychologist, 62(7), 671.

Martin, A., Kelly, P., Boyle, J., Corlett, F., \& Reilly, J. J. (2016). Contribution of walking to school to individual and population moderate-vigorous intensity physical activity: systematic review and meta-analysis. Pediatric Exercise Science, 28(3), 353-363.

Martin, S. L., Moeti, R., \& Pullen-Seufert, N. (2009). Implementing safe routes to school: Application for the socioecological model and issues to consider. Health Promotion Practice, 10(4), 606-614.

Masia, C. L., \& Chase, P. N. (1997). Vicarious learning revisited: A contemporary behavior analytic interpretation. Journal of Behavior Therapy and Experimental Psychiatry, 28(1), 41-51.

Mayhew, E., Uprichard, E., Beresford, B., Ridge, T., \& Bradshaw, J. (2004). Children and childhood in the United Kingdom. In A. Jensen (Ed.), Children's welfare in ageing Europe (pp. 403-457). Trondheim: Norwegian Centre for Child Research.

McDonald, N. C., Brown, A. L., Marchetti, L. M., \& Pedroso, M. S. (2011). US school travel, 2009: An assessment of trends. American Journal of Preventive Medicine, 41(2), 146-151.

McEwan, D., Harden, S. M., Zumbo, B. D., Sylvester, B. D., Kaulius, M., Ruissen, G. R., ... Beauchamp, M. R. (2016). The effectiveness of multi-component goal setting interventions for changing physical activity behaviour: A systematic review and meta-analysis. Health Psychology Review, 10(1), 67-88.

McMillan, T., Day, K., Boarnet, M., Alfonzo, M., \& Anderson, C. (2006). Johnny walks to school-does Jane? Sex differences in children's active travel to school. Children, Youth and Environments, 16(1), 75-89.

McMillan, T. E. (2005). Urban form and a child's trip to school: The current literature and a framework for future research. Journal of Planning Literature, 19(4), 440-456.

Mendoza, J. A., Watson, K., Baranowski, T., Nicklas, T. A., Uscanga, D. K., Nguyen, N., \& Hanfling, M. J. (2010). Ethnic minority children's active commuting to school and association with physical activity and pedestrian safety behaviors. The Journal of Applied Research on Children: Informing Policy for Children at Risk, 1(1), 1.

Mendoza, J. A., Watson, K., Baranowski, T., Nicklas, T. A., Uscanga, D. K., \& Hanfling, M. J. (2011). The walking school bus and children's physical activity: a pilot cluster randomized controlled trial. Pediatrics, 128(3), doi:10.1542/peds.2010-3486.

Mineka, S., \& Oehlberg, K. (2008). The relevance of recent developments in classical conditioning to understanding the etiology and maintenance of anxiety disorders. Acta Psychologica, 127(3), 567-580. doi:10.1016/j.actpsy.2007.11.007

Mitchell, H., Kearns, R. A., \& Collins, D. C. A. (2007). Nuances of neighbourhood: Children's perceptions of the space between home and school in Auckland, New Zealand. Geoforum, 38(4), 614-627.

Mitra, R. (2013). Independent mobility and mode choice for school transportation: A review and framework for future research. Transport Reviews, 33(1), 21-43.

Murtagh, S., Rowe, D. A., Elliott, M. A., McMinn, D., \& Nelson, N. M. (2012). Predicting active school travel: The role of planned behavior and habit strength. International Journal of Behavioral Nutrition and Physical Activity, 9(1), 65.

Nelson, N. M. (2007). The health impact and physical environmental determinants of active commuting to school. Dublin: Dublin City University.

Nevin, J. A. (2012). Resistance to extinction and behavioral momentum. Behavioural Processes, 90(1), 89-97.

Newson, L., \& Flint, B. (2011). Applied psychology and obesity management. Obesity in the UK: A Psychological Perspective, 26, 26-38.

Nilsen, P. (2015). Making sense of implementation theories, models and frameworks. Implementation Science, $10(1), 53$. Nord, W. R., \& Peter, J. P. (1980). A behavior modification perspective on marketing. Journal of Marketing, 44(Spring), 36-47.

O'Brien, N., McDonald, S., Araújo-Soares, V., Lara, J., Errington, L., Godfrey, A., ... White, M. (2015). The features of interventions associated with long-term effectiveness of physical activity interventions in adults aged 55-70 years: A systematic review and meta-analysis. Health Psychology Review, 9(4), 417-433.

Ortu, D., Becker, A. M., Woelz, T. A. R., \& Glenn, S. S. (2012). An iterated four-player prisoner's dilemma game with an external selecting agent: A metacontingency experiment. Revista Latinoamericana de Psicología, 44(1), 111-120.

Panter, J., Corder, K., Griffin, S. J., Jones, A. P., \& van Sluijs, E. M. F. (2013). Individual, socio-cultural and environmental predictors of uptake and maintenance of active commuting in children: Longitudinal results from the SPEEDY study. International Journal of Behavioral Nutrition and Physical Activity, 10(1), 83. 
Panter, J. R., Jones, A. P., \& Van Sluijs, E. M. F. (2008). Environmental determinants of active travel in youth: A review and framework for future research. International Journal of Behavioral Nutrition and Physical Activity, 5, 34.

Panter, J. R., Jones, A. P., van Sluijs, E. M. F., \& Griffin, S. J. (2010). Attitudes, social support and environmental perceptions as predictors of active commuting behaviour in school children. Journal of Epidemiology and Community Health, 64(1), 41-48. doi:10.1136/jech.2009.086918

Pavlov, I. P. (1927). Conditioned reflexes. New York: Dover.

Pierce, W. D., \& Cheney, C. D. (2004). Behavior analysis and learning (3rd ed.). Mahwah, NJ: Erlbaum.

Pikora, T., Giles-Corti, B., Bull, F., Jamrozik, K., \& Donovan, R. (2003). Developing a framework for assessment of the environmental determinants of walking and cycling. Social Science \& Medicine, 56(8), 1693-1703.

Pont, K., Ziviani, J., Wadley, D., \& Abbott, R. (2011). The model of children's active travel (M-CAT): A conceptual framework for examining factors influencing children's active travel. Australian Occupational Therapy Journal, 58(3), $138-144$.

Pont, K., Ziviani, J., Wadley, D., Bennett, S., \& Abbott, R. (2009). Environmental correlates of children's active transportation: A systematic literature review. Health \& Place, 15(3), 849-862.

Pooley, C., Whyatt, D., Walker, M., Davies, G., Coulton, P., \& Bamford, W. (2010). Understanding the school journey: Integrating data on travel and environment. Environment and Planning A, 42(4), 948-965. doi:10.1068/a41405

Reynolds, B. S., \& Hayes, L. J. (2017). Parallels and incongruities between musical and verbal behaviors. The Psychological Record, 67(3), 413-421.

Romero, V. (2015). Children's experiences: Enjoyment and fun as additional encouragement for walking to school. Journal of Transport \& Health, 2(2), 230-237.

Saelens, B. E., \& Handy, S. L. (2008). Built environment correlates of walking: A review. Medicine and Science in Sports and Exercise, 40(7 Suppl.), S550.

Saiyed, S., \& Kennedy, J. (2006). Safe and Active Routes to School Program: Experiences and Lessons Learned. Paper presented at the 2006 ITE Annual Meeting and Exhibit Compendium of Technical Papers, Milwaukee, WI.

Sallis, J. F., \& Owen, N. 1999. Physical activity and behavioral medicine. Thousand Oaks, CA: Sage.

Sirard, J. R., Alhassan, S., Spencer, T. R., \& Robinson, T. N. (2008). Changes in physical activity from walking to school. Journal of Nutrition Education and Behavior, 40(5), 324-326.

Sirard, J. R., \& Pate, R. R. (2001). Physical activity assessment in children and adolescents. Sports Medicine, 31(6), 439-454.

Sirard, J. R., \& Slater, M. E. (2008). Walking and bicycling to school: A review. American Journal of Lifestyle Medicine, 2(5), $372-396$.

Skinner, B. F. (1945). The operational analysis of psychological terms. Psychological Review, 52(5), 270.

Skinner, B. F. (1953). Science and human behavior. New York: Macmillan.

Skinner, B. F. (1957). Verbal behavior. New York, NY: Appleton-Century-Crofts.

Skinner, B. F. (1981). Selection by consequences. Science, 213(4507), 501-504.

Strohacker, K., Galarraga, O., \& Williams, D. M. (2014). The impact of incentives on exercise behavior: A systematic review of randomized controlled trials. Annals of Behavioral Medicine, 48(1), 92-99.

Swinburn, B., Egger, G., \& Raza, F. (1999). Dissecting obesogenic environments: The development and application of a framework for identifying and prioritizing environmental interventions for obesity. Preventive Medicine, 29(6), 563-570.

Trapp, G., Giles-Corti, B., Christian, H., Bulsara, M., Timperio, A., McCormack, G., \& Villanueva, K. (2011). On your bike! A cross-sectional study of the individual, social and environmental correlates of cycling to school. The International Journal of Behavioral Nutrition and Physical Activity, 8, 123.

Trapp, G. S. A., Giles-Corti, B., Christian, H. E., Bulsara, M., Timperio, A. F., McCormack, G. R., \& Villaneuva, K. P. (2012). Increasing children's physical activity individual, social, and environmental factors associated with walking to and from school. Health Education \& Behavior, 39(2), 172-182.

Van Der Ploeg, H. P., Merom, D., Corpuz, G., \& Bauman, A. E. (2008). Trends in Australian children traveling to school $1971-$ 2003: Burning petrol or carbohydrates? Preventive Medicine, 46(1), 60-62.

Van Kann, D. H. H., Kremers, S. P. J., de Vries, S. I., de Vries, N. K., \& Jansen, M. W. J. (2016). Parental active transportation routines (PATRns) as a moderator of the association between neighborhood characteristics and parental influences and active school transportation. Environment and Behavior, 48(7), 946-965.

Vichi, C., Andery, M. A. P. A., \& Glenn, S. S. (2009). A metacontingency experiment: The effects of contingent consequences on patterns of interlocking contingencies of reinforcement. Behavior and Social Issues, 18, 41.

Wong, B. Y., Faulkner, G., \& Buliung, R. (2011). GIS measured environmental correlates of active school transport: A systematic review of 14 studies. International Journal of Behavioral Nutrition and Physical Activity, 8(39), 1-22.

Yang, Y., Ivey, S. S., Levy, M. C., Royne, M. B., \& Klesges, L. M. (2016). Active travel to school: Findings from the survey of US health behavior in school-aged children, 2009-2010. Journal of School Health, 86(6), 464-471.

Yang, Y., Schlossberg, M., Parker, R., \& Johnson, B. (2010). Understanding school travel: How residential location choice and the built environment affect trips to school (OTREC-RR-10-01). Portland, OR: Transportation Research and Education Center (TREC).

Zentall, T. R., Galizio, M., \& Critchfield, T. S. (2002). Categorization, concept learning, and behavior analysis: An introduction. Journal of the Experimental Analysis of Behavior, 78(3), 237-248.

Zubrick, S. R., Wood, L., Villanueva, K., Wood, G., Giles-Corti, B., \& Christian, H. (2010). Nothing but fear itself: Parental fear as a determinant of child physical activity and independent mobility. Melbourne: Victorian Health Promotion Foundation (VicHealth). 